\title{
Reproductive health knowledge and services utilization among rural adolescents in east Gojjam zone, Ethiopia: a community-based cross-sectional study
}

Amanuel Alemu Abajobir ${ }^{1 *}$ and Assefa Seme ${ }^{2}$

\begin{abstract}
Background: According to World Health Organization, adolescents are people between 10 and 19 years of age; one-fifth of Ethiopian population constitutes adolescents and four-fifth live in rural areas. Local evidence about adolescents' reproductive health knowledge, services utilization and associated factors are relevant to design age-appropriate program interventions and strategies. Hence, this study assessed the level of reproductive health knowledge and services utilization among rural adolescents in Machakel district, Northwest Ethiopia.

Methods: A community-based cross-sectional study was conducted to assess the level of reproductive health knowledge and services utilization of rural adolescents in Machakel district. The study employed both quantitative and qualitative methods. A systematic random sampling technique was used to select 415 adolescents from eligible households. Data were collected using pre-tested structured questionnaires and in-depth interview guides. The data were entered into Epi Info and analyzed by SPSS software for windows. Univariate, bivariate and multivariate analyses were done.
\end{abstract}

Result: More than two-third (67\%) of the adolescents had knowledge about reproductive health. Age (AOR $=3.77$, 95\% Cl: 3.1-8.98), living arrangement ( $\mathrm{AOR}=2.21,95 \% \mathrm{Cl}: 1.81-6.04$ ) and economic status ( $\mathrm{AOR}=3.37,95 \% \mathrm{Cl}: 1.65-6.87$ ) were associated with reproductive health knowledge. However, only one-fifth (21.5\%) of the adolescents had ever used reproductive health services including family planning, sexually transmitted infections treatment and information, education and communication. Reproductive health services utilization was significantly associated with age ( $A O R=2.18$, 95\% Cl: 1.13-8.03) and knowledge for reproductive health (AOR $=1.23$, 95\% Cl: 1.23-4.21). Parent disapproval, lack of basic information and pressure from partners were found to deter adolescents from accessing and using reproductive health services.

Conclusion: Reproductive health knowledge and services utilization amongst rural adolescents remained low. Age and economic status were significantly associated with reproductive health knowledge; moreover, reproductive health services utilization was associated with age and respective knowledge for reproductive health.

Community-conversation in line with adolescent-to-adolescent-counseling, peer education and parent-adolescent communication should address sensitive topics such as sex education and life skill development.

Keywords: Rural adolescent, Reproductive health knowledge, Services utilization

\footnotetext{
* Correspondence: amanuel_alemu@yahoo.com

'Public Health Department, Debremarkos University, P.O. Box: 269,

Debremarkos, Ethiopia

Full list of author information is available at the end of the article
} 


\section{Background}

According to World Health Organization (WHO), adolescents are people between 10 and 19 years of age; they make $20 \%$ of the world's population, of whom $85 \%$ live in developing countries. Adolescence is characterized by significant physiological, psychological and social changes that put adolescents for high risk sexual and reproductive health (SRH) problems. This has partially been because adolescents were considered to be relatively healthy, without a heavy "burden of disease" [1,2].

The concern about adolescent sexual and reproductive health (ASRH) has grown due to unprecedented increasing rates of sexual activity, early pregnancies and sexually transmitted infections (STI) including human immune deficiency virus (HIV) among adolescents [3,4].

Since the 1994 International Conference on Population Development (ICPD) in Cairo, Egypt, adolescent-friendly reproductive health services (AFRHS) have been recognized as an appropriate and effective strategy to address SRH needs of adolescents [5]. Nevertheless, the needs of the young people remain poorly understood or served in many parts of the world [6].

Despite $35 \%$ of the world population being in the 10-24 age groups, the reproductive health $(\mathrm{RH})$ needs of adolescents have neither been researched nor addressed adequately [7]. Early and unprotected sexual activity and misconceptions about HIV/AIDS are prevalent among rural adolescents [8].

There are few studies on knowledge, attitude and practice of adolescents in relation to their $\mathrm{RH}$ in Ethiopia showing a significant discrepancy between knowledge about and the level of services utilization in particular and poor access to RH services in general [9-12].

As "age-appropriate" interventions to a particular setting are desirable to address the diverse needs and contexts of adolescents' RH, studying their knowledge, services utilization and associated factors is relevant to design appropriate program interventions and strategies in the local context $[9,13]$.

In Ethiopia, nearly $20 \%$ are young people of whom four-fifth live in rural parts of the country [14]. However, few attempts have been made particularly in rural settings for addressing their critical concerns or providing them with the necessary SRH services.

\section{Methods}

\section{Study area and period}

The study was conducted in Machakel district, northwest Ethiopia, in February 2012. The district comprised 24 rural kebeles (the smallest administrative unit). Based on the 2007 census and according to regional population projection in 2009, the district had a total population of 128,655 , of whom $8749(6.8 \%)$ live in urban and 119,928 $(93.2 \%)$ in rural areas; $44,386(34.5 \%)$ were people of age group 10-24 years. The total number of households $(\mathrm{HH})$ in the district was 29,918 and the average population density was 936 people per square kilometer.

\section{Study design}

A community-based cross-sectional study was conducted to assess the level of RH knowledge and services utilization of rural adolescents in Machakel district. The study employed both quantitative and qualitative methods.

\section{Source and study population}

All rural adolescents who lived in Machakel district for the last six months were the source population. Eligible adolescents from the selected $\mathrm{HH}$ were the study population.

\section{Sample size}

The sample size was calculated using single population proportion formula by taking the proportion (p) of modern contraceptive utilization by adolescents to be $57 \%$ [12].

The assumptions of 95\% confidence level (level of significance, $\alpha=0.05), 5 \%$ margin of error and $10 \%$ nonresponse were used to determine the sample size. Accordingly, the total sample size was 415 .

\section{Sampling \\ Quantitative study}

Six kebeles were selected randomly among the 24 rural kebeles in the district. Sample HH were proportionally allocated for each eligible kebele. Systematic random sampling technique was used to select each $\mathrm{HH}$. One adolescent in the age group of 10-19 year was interviewed. If there were more than one adolescent in a particular $\mathrm{HH}$, one of them was selected randomly.

\section{Qualitative study}

For in-depth exploration of adolescents' RH knowledge and pattern of services utilization including their experiences, feelings and perceptions, participants were selected for in-depth interview (IDI) purposively; it included those who were not participated in quantitative study and could express themselves well.

\section{Data collection procedure \\ Quantitative data}

Pre-tested structured questionnaires were prepared by reviewing previous studies on the problem of interest $[8,12-16]$.

The questionnaire contained three parts:

1. Demographic, social and economic characteristics,

2. Knowledge on RH-related topics (fertility, contraception, STIs/HIV/AIDS, voluntary counseling and testing (VCT)) and

3. Patterns of RH services utilization. 
Six health extension workers (HEW) collected the data using face-to-face interviews.

\section{Qualitative data}

An IDI was used to get insight into issues that could not be addressed by the quantitative survey. Open-ended questions were used to guide the interview. The interviews were assisted by a reporter, note takers and supported by a tape recorder.

\section{Data quality management}

Pre-test was undertaken on $10 \%$ of the sample to examine the reliability and construct the validity of the instrument. Intensive training was given for data collectors and supervisors on the objective of the study, contents of the questionnaire and how to maintain confidentiality and privacy of the study subjects. The collected data were checked by the principal investigators for any incompleteness and/or inconsistency. During data cleaning, logical checking techniques were employed to identify errors.

\section{Data processing and analysis Quantitative data}

Data were entered in to Epi Info 3.5.1 and transferred to SPSS 16.0 for windows for statistical analysis. Data exploration was done to visualize the general feature of the data. After exploration, percentages were used to assess the level of RH knowledge and services utilization among rural adolescents. Data were presented using tables and graphs accordingly.

To determine the association between different factors and $\mathrm{RH}$ knowledge and services utilization, a logistic regression model was employed and two steps were followed. First, each variable was entered into a binary logistic regression model. Second, variables which were significant at p-value of 0.05 were fitted into multiple logistic regression model to identify independent factors of RH knowledge and services utilization. Variables that remained significant at p-value of 0.05 in the final multivariate logistic regression model were identified as independent factors of $\mathrm{RH}$ knowledge and services utilization.

\section{Qualitative data}

Responses were transcribed and translated into Amharic (local language) and then to English by maintaining the context of the responses. Important findings were summarized, narrated and incorporated in the result.

\section{Study variables \\ Dependent}

- Reproductive health knowledge

- Reproductive health services utilization

\section{Independent}

- socio-demography variables

- socio- economic variables

- reproductive characteristics

\section{Definitions}

\section{Reproductive health knowledge}

The adolescents were asked questions which covered the expectations about male and female adolescents' fertility, FP, STI and VCT for HIV/AIDS and services expected to be provided to and utilized by adolescents in the study area including information, education and communications about health services for $\mathrm{RH}$. The investigators developed an index which summarized adolescents' knowledge about the above issues that assigned a score of $\mathbf{1}$ for each "Yes" or correct response and $\mathbf{0}$ for "No" or incorrect response.

Key

1. Knowledgeable if the summary index equals or greater than the mean.

2. Not knowledgeable if the summary index is less than the mean.

\section{Reproductive health services utilization}

Use of any sexual and reproductive health services including medical checkup, consultations, FP, health education on HIV/AIDS and STI treatment rendered in healthcare centers.

\section{Ethical consideration}

Ethical clearance was obtained from the Research and Ethical Committee of the School of Public Health of Addis Ababa University. Permission was obtained from Machakel district administration and health bureau. Data collection was conducted after verbal consent and/ or assent had been obtained.

\section{Results}

\section{Quantitative findings}

Socio-demographic and socio-economic characteristics

Three hundred eight one rural adolescents participated in the study yielding $92 \%$ response rate.

The mean age of the adolescents was 14.6 \pm 4.1 years and more than half, 190 (50.7\%), were males. Amhara constituted 372 (99.3\%) ethnic group and almost all, 371 (99.2\%), were Orthodox Christians. Most adolescents, $319(85.1 \%)$, were single and more than four-fifth, 304 (81.1\%), had ever attended formal education. Half of the families could not read and write. The mean family size was $4.43 \pm 1.73$. Two hundred twenty three (60.6\%) adolescents were living with both parents. Two hundred 
and fifty one of the adolescents (67.4\%) possessed means of communication (Table 1).

\section{Reproductive health knowledge of rural adolescents}

The mean age at menarche for female adolescents was $13.8 \pm 1.4$ years. Two hundred (53.5\%) of the adolescents

\section{Table 1 Socio-demographic and socio-economic characteristics of rural adolescents in Machakel district, northwest Ethiopia, February 2012}

\begin{tabular}{|c|c|c|}
\hline Variables & Frequency $(n=375)$ & Percent \\
\hline \multicolumn{3}{|l|}{ Sex } \\
\hline Male & 190 & 50.7 \\
\hline Female & 185 & 49.3 \\
\hline \multicolumn{3}{|l|}{ Age } \\
\hline $10-14$ & 127 & 33.9 \\
\hline $15-19$ & 248 & 66.1 \\
\hline Mean & $14.6 \pm 4.1$ & \\
\hline \multicolumn{3}{|l|}{ Marital status } \\
\hline Single & 319 & 85.1 \\
\hline Ever married & 56 & 14.9 \\
\hline \multicolumn{3}{|c|}{ Ever attended school } \\
\hline Yes & 304 & 81.1 \\
\hline No & 71 & 18.9 \\
\hline \multicolumn{3}{|c|}{ Educational status $(n=304)$} \\
\hline Elementary & 145 & 47.7 \\
\hline Secondary & 159 & 52.3 \\
\hline \multicolumn{3}{|c|}{ Current schooling } \\
\hline In-school & 258 & 68.9 \\
\hline Out-of-school & 117 & 31.1 \\
\hline \multicolumn{3}{|c|}{ Current living arrangement } \\
\hline Both parents & 227 & 60.6 \\
\hline Single parent & 99 & 26.4 \\
\hline Husband/wife & 43 & 11.4 \\
\hline Other & 6 & 1.7 \\
\hline \multicolumn{3}{|l|}{ Family size } \\
\hline$</=5$ & 143 & 38.1 \\
\hline$>5$ & 232 & 61.9 \\
\hline Mean & $4.43 \pm 1.73$ & \\
\hline \multicolumn{3}{|c|}{ Current occupational status } \\
\hline Student & 258 & 68.9 \\
\hline Farmer & 42 & 11.2 \\
\hline Housewife & 39 & 10.4 \\
\hline Merchant & 31 & 8.2 \\
\hline Daily laborer & 6 & 1.6 \\
\hline \multicolumn{3}{|c|}{ Any means of communication } \\
\hline Yes & 251 & 67.4 \\
\hline No & 124 & 32.6 \\
\hline
\end{tabular}

responded that a girl could get pregnant the first time she had sex and the age at which it could occur was mentioned as "during puberty" by over a third 138 (36.6\%), followed by "after puberty" 141 (37.7\%) and "before 10 years" of age 5 (1.3\%); however, a significant proportion of the adolescents, 91 (24.3\%), did not know the age at which pregnancy could occur.

Regarding menstrual cycle with high chance of getting pregnancy, only $53(14.2 \%)$ responded it was in the "middle of the cycle" and a considerable proportion of the study subjects, 118 (31.3\%), did not know at which cycle it would occur at all. The male counterpart could be mature or physically made a girl pregnant "during puberty" was reported only by 129 (34.4\%) of the adolescents and even 105 (28.2\%) did not know when the boy would be physiologically mature to do so. Misconceptions of most physiologic changes taking place during adolescence period were reported by significant proportion of the study participants. This result is lower than the finding from China where $29.4 \%$ of rural migrant adolescents had knowledge about fertility issues [13]. A basic knowledge of the physiology of reproduction and fertility is important especially for the successful practice of coitus related methods such as periodic abstinence.

The successful use of such methods depends in part on an understanding of when during the ovulatory cycle a woman is most likely to conceive [14]. Most rural adolescents in this study did not know changes marking boys entering into adulthood and girls into womanhood which contradicts with the study in India, where nearly half of the adolescents were well informed about such an issue [17].

Adolescents' overall knowledge was evaluated by summarizing all reproductive health-related responses. Accordingly, the mean knowledge score was $10.01 \pm 2.7$.

Two-third, 251 (67\%), of the adolescents had knowledge about RH based on the mean score (Table 2). More than four-fifth of the rural adolescents had knowledge about ways of avoiding unwanted pregnancy and the majority mentioned oral contraceptive pills (OCP) but long-acting and permanent contraception methods such as norplant, intrauterine devices and sterilization were mentioned by few adolescents (Figure 1).

Over two-third 255 (68\%) of the rural adolescents had ever heard diseases that could be transmitted by sexual intercourse; gonorrhea and HIV/AIDS were the major STI mentioned by 118 (46.4\%) and 108 (42.5\%) of the adolescents respectively. Genital ulcer was indicated as the sign/symptom of such diseases by more than half of the study participants, 141 (55.2\%), followed by pain during urination $22(8.6 \%)$ and abnormal genital discharge 13 (4.9\%); however, more than one-fifth did not know any manifestation of such infections. Most of the adolescents, 343 (91.5\%), had ever heard about HIV/ 
Table 2 Reproductive health knowledge of rural adolescents in Machakel district, northwest Ethiopia, February 2012

\begin{tabular}{|c|c|c|}
\hline Variables & Frequency $(n=375)$ & $\%$ \\
\hline \multicolumn{3}{|c|}{ Age at menarche (years) $n=185$} \\
\hline $10-14$ & 121 & 65.4 \\
\hline $15-19$ & 64 & 34.6 \\
\hline Mean age at menarche & $3.8 \pm 1.4$ & \\
\hline \multicolumn{3}{|c|}{ A girl gets pregnant the $1^{\text {st }}$ time she has sex } \\
\hline Yes & 200 & 53.5 \\
\hline No & 175 & 46.5 \\
\hline \multicolumn{3}{|c|}{ Know ways of avoiding pregnancy } \\
\hline Yes & 282 & 75.1 \\
\hline No & 93 & 24.9 \\
\hline \multicolumn{3}{|l|}{ Know about STIs } \\
\hline Yes & 236 & 63.0 \\
\hline No & 139 & 37.0 \\
\hline \multicolumn{3}{|l|}{ Know about HIV/AIDS } \\
\hline Yes & 297 & 79.5 \\
\hline No & 78 & 20.5 \\
\hline \multicolumn{3}{|c|}{ HIV/AIDS can be acquired with $1^{\text {st }}$ contact } \\
\hline Yes & 210 & 56.2 \\
\hline No & 165 & 43.8 \\
\hline \multicolumn{3}{|c|}{ Know any way to prevent HIV/AIDS } \\
\hline Yes & 270 & 72.0 \\
\hline No & 105 & 28.0 \\
\hline \multicolumn{3}{|l|}{ Know about VCT } \\
\hline Yes & 243 & 65.0 \\
\hline No & 132 & 35.0 \\
\hline \multicolumn{3}{|l|}{ Overall knowledge } \\
\hline Knowledgeable & 251 & 67.0 \\
\hline Not knowledgeable & 124 & 33.0 \\
\hline
\end{tabular}

AIDS and indicated unsafe sexual intercourse as the major way of acquiring the disease 198 (66.6\%) followed by sharing sharp materials like needles and syringes 66 (22.2\%); only 18 (5.9\%) responded mother-to-child transmission as a route of acquiring the virus indicating a concerted effort by all stakeholders to educate and raise awareness about this route of transmission in the general population and among the adolescents in particular. More than four-fifth of the adolescents, 279 (81.2\%), responded as there were mechanisms through which STI and HIV/AIDS could be avoided/prevented. Abstaining from sexual intercourse was the major means to prevent oneself from acquiring such infections, 188 (67.4\%), followed by avoiding unsafe or casual sex 41 (14.8\%) and remaining faithful to a partner 39 (14\%). A person could not get HIV with the first sexual contact and through careful looking at a person HIV/AIDS status of an individual would be determined were reported by $41.1 \%$ and $12 \%$ of the adolescents respectively.

Two hundred seventy (72\%) have ever heard about VCT and described reduction of the dissemination of HIV, enabling to know one's disease status and increasing confidence as its main advantages.

\section{Pattern of reproductive health services utilization among rural adolescents}

Almost 4 in 10, 144 (38.3\%), adolescents had ever heard about RH services and reported health professionals 116 (80.4\%) as the main sources of information followed by radio $22(15.5 \%)$, television $4(3.1 \%)$ and print media (posters/leaflets) 2 (1\%).

Only about one-fifth 31 (21.5\%) of adolescents had ever used RH services and 6 (18.8\%) visited service rendering centres in the last 6 months. For majority of the adolescents, government health facilities 17 (54.8\%), health posts $8(25.8 \%)$ and private health facilities 5 (16.1\%) were the preferred health institutions. There was also a sizeable contribution of traditional healers.

Effectiveness, proximity and treatment for free were indicated as the reasons to visit these institutions. The services rendered in these facilities included medical checkup 12 (39.8\%), STI treatment 8 (23.1\%), delivery 6 (21.1\%) and other 5 (16\%) such as FP, abortion/post abortion care, VCT and information, education and communication (IEC). Seeking FP was reported by $30 \%$ of the rural adolescents.

About four-fifth (78.2\%) of rural adolescents were familiar with OCP; however, long-acting contraceptive methods were less likely used by the adolescents.

Healthcare professionals with the same sex were preferred by the majority of the adolescents 18 (58.9\%). Among other factors, parent disapproval, lack of information and peer pressure were reported to hinder adolescents from accessing RH services (Figure 2).

The main obstacles from the adolescents' perspective refraining/preventing them from getting $\mathrm{RH}$ services from health institutions were mentioned as never thought of the services, unnecessary of the services, lack of knowledge and being young/healthy were listed by 128 (50.6\%), $87(34.4 \%), 65(24.3 \%)$ and $44(17.4 \%)$ of the adolescents respectively among others.

Three quarters of the adolescents had never discussed $\mathrm{RH}$ topics with their parents due to its worthlessness 63 (24.9\%), fear 188 (74.3\%), social and cultural taboos 52 (20.6\%) and others 18 (7.1\%).

The majority of the adolescents prefer to discuss $\mathrm{RH}$ issues with friends/peers 174 (46.4\%), followed by health professionals 105 (28\%) and mothers 41 (10.8\%). 


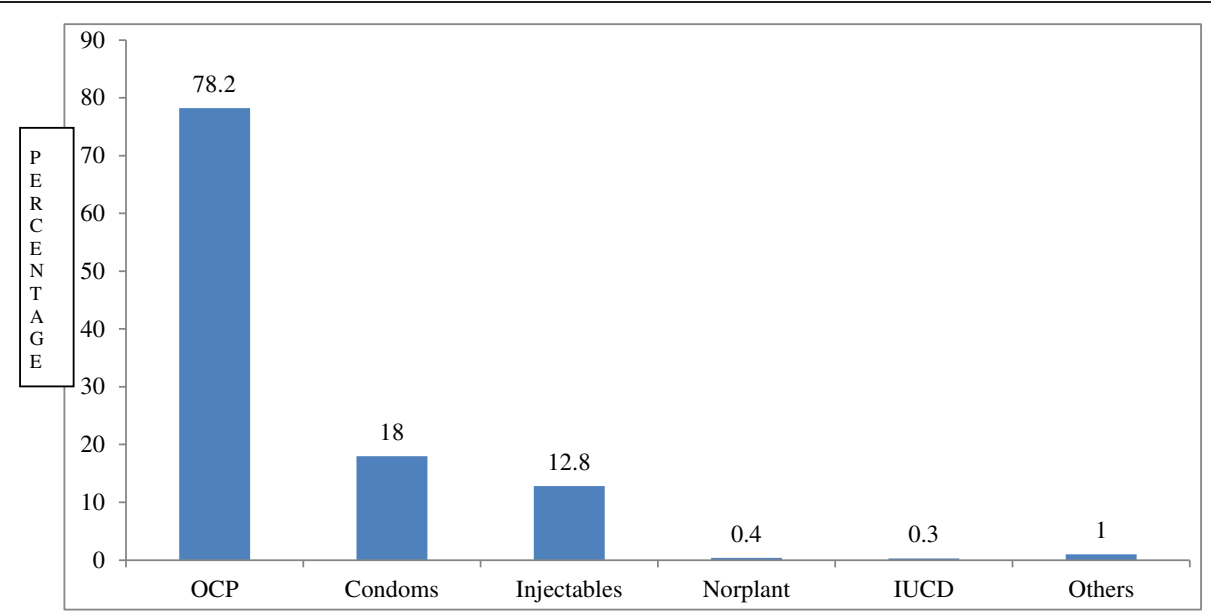

Figure 1 Knowledge of contraception methods of rural adolescents, Machakel district, northwest Ethiopia, February 2012.

According to this study, only 105 (28\%) of the rural adolescents were well informed about $\mathrm{RH}$ such as contraceptives and other issues. Schools and friends were found to be important sources of SRH information for rural adolescents (Table 3).

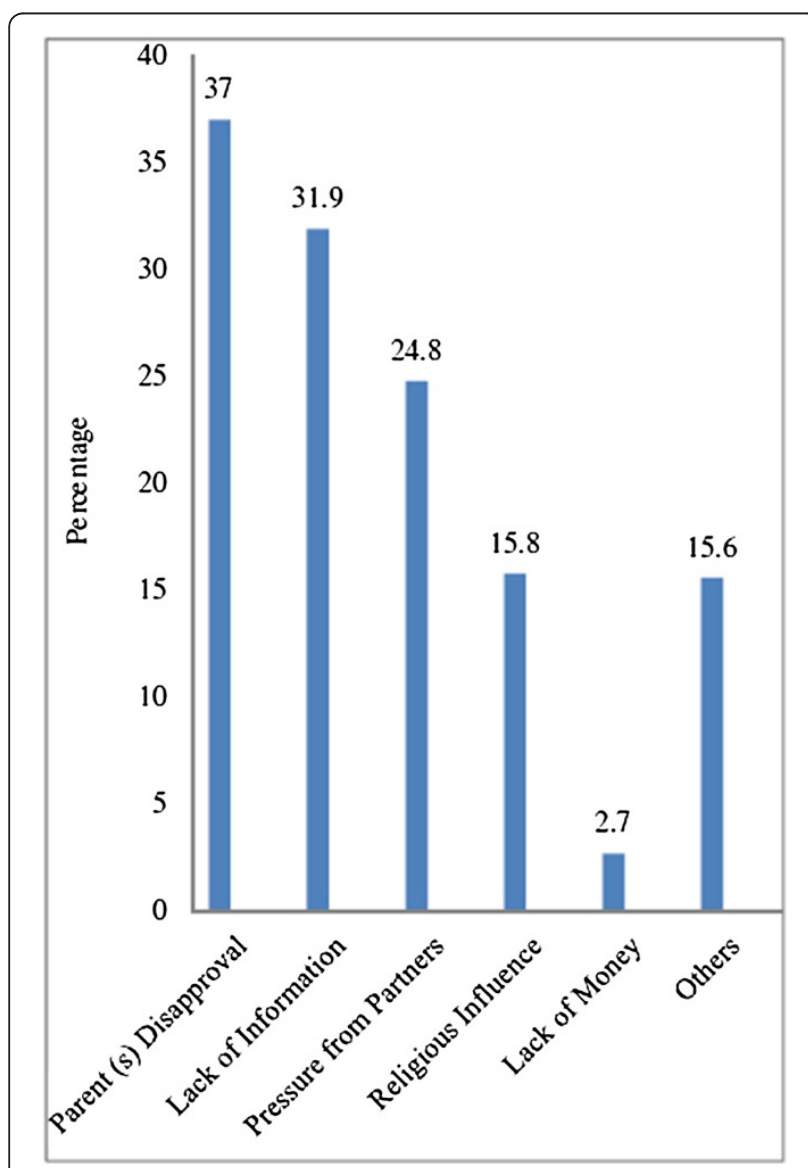

Figure 2 Factors hindering RH services utilization among rural adolescents, Machakel district, northwest Ethiopia, February 2012.
Table 3 Reproductive health services utilization and related factors among rural adolescents of Machakel district, northwest Ethiopia, February 2012

\begin{tabular}{lcc}
\hline Variables & Frequency $(\mathbf{n}=\mathbf{= 3 7 5})$ & Percent \\
\hline Ever heard of RHS & & \\
Yes & 144 & 38.3 \\
No & 231 & 61.7
\end{tabular}

Ever utilized RHS $(n=144)$

Yes

$31 \quad 21.5$

No

113

79.5

Visited RHS centres in the last 6 months $(n=144)$

Yes

6

No

138

Main obstacles preventing from getting RHS

Never thought of the services 128

Services not necessary

50.6

34.4

Lack of knowledge

Too young/healthy

Ever discussed RH topics with parents

Yes

No

253

Reasons for not discussing RH topics ( $n=253$ )

$\begin{array}{lcc}\text { Not necessary } & 63 & 24.9 \\ \text { Fear } & 188 & 74.3 \\ \text { Cultural restriction } & 52 & 20.6 \\ \text { Others } & 18 & 7.1\end{array}$

Well informed about RHS 


\section{Association of socio-demographic and socio-economic characteristics and $\mathrm{RH}$ knowledge}

In order to understand the social and demographic factors related to $\mathrm{RH}$ knowledge, a logistic regression analysis was done. Among the socio-demographic and economic characteristics of the respondents' sex, age, educational status, living arrangement (living with grandparents and other relatives) and family income were found to have statistically significant association with $\mathrm{RH}$ knowledge.

However, adolescents' marital status, religion, ethnicity, history of schooling, occupational status, families' educational background, family size and means of communication were found to have no statistically significant association. Accordingly, female adolescents were found to have less knowledge than their male counterparts for $\mathrm{RH}(\mathrm{COR}=0.56,95 \% \mathrm{CI}:$ 0.11-0.89). Late adolescence (15-19 year) was positively associated with RH knowledge $(\mathrm{COR}=1.29,95 \% \mathrm{CI}$ : 1.01-3.63). Reproductive health knowledge was higher among secondary school than primary school adolescents $(\mathrm{COR}=1.35,95 \% \mathrm{CI}$ : 1.06-6.12) and it was higher among in-school adolescents than their out-of-school counterparts $(\mathrm{COR}=1.05,95 \% \mathrm{CI}$ : 1.03-4.98). Adolescents mostly living with their grandparents and other relatives had more knowledge $(\mathrm{COR}=2.69,95 \% \mathrm{CI}: 1.48-14.99)$. It was two times higher for adolescents from rich families than their poor counterparts $(\mathrm{COR}=2.15$, 95\% CI: $1.67-6.98)$.

After adjusting for socio-demographic and economic variables, age, family arrangement and perceived family income showed statistically significant association with $\mathrm{RH}$ knowledge. The odd of $\mathrm{RH}$ knowledge was about 4 times higher among 15-19 years adolescents than 10-14 years $(\mathrm{AOR}=3.77,95 \% \mathrm{CI}: 3.1-8.98)$. It was also about 2 times higher among adolescents living with their grandparents and other relatives than those who were living with their biological parents and spouse $(\mathrm{AOR}=2.21$, 95\% CI: 1.81- 6.04). Moreover, adolescents from rich families had 3 times more knowledge than poor families $(\mathrm{AOR}=3.37,95 \% \mathrm{CI}$ : 1.65-6.87) (Table 4).

\section{Association of socio-demographic and socio-economic} characteristics and reproductive health services utilization Socio-demographic and economic characteristics including, marital status, religion, ethnicity, education, families' educational background, family size, family income and means of communication had no statistically

Table 4 Bivariate and multivariate analysis of socio-demographic and socio-economic characteristics and reproductive health knowledge among rural adolescents of Machakel district, northwest Ethiopia, February 2012

\begin{tabular}{|c|c|c|c|c|}
\hline \multirow[t]{2}{*}{ Factors } & \multicolumn{2}{|c|}{ RH knowledge } & \multirow[t]{2}{*}{ COR $[95 \% \mathrm{Cl}]$} & \multirow[t]{2}{*}{ AOR $[95 \% \mathrm{Cl}$} \\
\hline & Yes & No & & \\
\hline \multicolumn{5}{|l|}{ Sex } \\
\hline Male & $117(46.6)$ & $73(58.9)$ & 1.00 & 1.00 \\
\hline Female & $134(53.4)$ & $51(41.1)$ & $0.56(0.11-0.89)$ & $0.39(0.47-1.34)$ \\
\hline \multicolumn{5}{|l|}{ Age (in years) } \\
\hline $10-14$ & $54(21.5)$ & $73(58.9)$ & 1.00 & 1.00 \\
\hline $15-19$ & $167(66.5)$ & $51(41.1)$ & $1.29(1.01-3.63)$ & $3.77(3.1-8.98)$ \\
\hline \multicolumn{5}{|c|}{ Level of school completed } \\
\hline Elementary & $106(42.2)$ & $53(42.7)$ & 1.00 & 1.00 \\
\hline Secondary & $105(57.8)$ & $39(57.3)$ & $1.37(1.06-6.12)$ & $1.35(1.06-6.12)$ \\
\hline \multicolumn{5}{|c|}{ Current schooling } \\
\hline In-school & $153(61)$ & $105(84.7)$ & $1.05(1.03-4.98)$ & $1.05(1.03-4.98)$ \\
\hline Out-of-school & $68(39)$ & $49(15.3)$ & 1.00 & 1.00 \\
\hline \multicolumn{5}{|c|}{ Living mostly with } \\
\hline Both parents & $117(46.6)$ & $90(23.6)$ & 1.00 & 1.00 \\
\hline Single parent & $65(17)$ & $21(5.5)$ & $0.94(0.57-1.53)$ & $0.94(0.57-1.53)$ \\
\hline Husband/wife & $32(8.3)$ & $6(1.6)$ & $0.95(0.48-1.87)$ & $0.95(0.48-1.87)$ \\
\hline Others & $11(2.8)$ & $7(1.6)$ & $2.69(1.48-14.9)$ & $2.21(1.81-6.04)$ \\
\hline \multicolumn{5}{|l|}{ Family income } \\
\hline Poor & 49 (19.5) & 94 (75.8) & 1.00 & 1.00 \\
\hline Medium & $61(24.3)$ & $24(19.4)$ & $1.1(0.58-2.1)$ & $1.1(0.58-2.1)$ \\
\hline Rich & $141(56.2)$ & $6(4.8)$ & $2.15(1.67-6.98)$ & $3.37(1.65-6.87)$ \\
\hline
\end{tabular}

Adjusted for sex, age, level of education, current schooling, living arrangement and family income. 
significant association with $\mathrm{RH}$ services utilization. However, sex, age, being in-school and educational status showed statistically significant association with RH services utilization.

Female adolescents less likely used RH services than their male counterparts (COR $=0.17,95 \% \mathrm{CI}$ : 0.14-0.33). $\mathrm{RH}$ services utilization was about 2 times higher among late adolescents $(\mathrm{COR}=1.5,95 \% \mathrm{CI}$ : 1.3-5.21). Secondary education adolescents less likely used RH services than elementary school counter parts $(\mathrm{COR}=0.57,95 \%$ CI: 1.48-0.93).

Furthermore, in-school adolescents used RH services 3 times higher than their out-of-school counterparts $(\mathrm{COR}=3.3$, 95\% CI: 2.51-6.43). After adjusting for possible confounding variables, age and educational status had statistically significant association with $\mathrm{RH}$ services utilization. Adolescents whose age ranges 15-19 years used RH services 2 times more likely than 10-14 years $(\mathrm{AOR}=2.18,95 \% \mathrm{CI}: 1.13-8.03)$. Adolescents with secondary education used $\mathrm{RH}$ services 2 times more likely than elementary school adolescents $(\mathrm{AOR}=2.41,95 \% \mathrm{CI}$ $(2.98,7.11))$ (Table 5).

Factors affecting reproductive health services utilization On bivariate analysis, $\mathrm{RH}$ services utilization was associated with IEC, adolescent-parent discussion of SHR topics and RH knowledge.

The likelihood of services uptake was about 4 times higher where there was adolescent-parent communication regarding $\mathrm{RH}$ topics $(\mathrm{COR}=3.70,95 \% \mathrm{CI}$ : 1.89-5.68). Adolescents having knowledge for $\mathrm{RH}$ had more likelihood of using $\mathrm{RH}$ services (COR $=1.46,95 \% \mathrm{CI}$ : 1.35-4.23).

On multivarite analysis, $\mathrm{RH}$ services utilization was associated with IEC, adolescent-parent discussion about SRH topics and RH knowledge.

The odds of RH services utilization was 3 times higher among rural adolescents who have ever heard about $\mathrm{RH}$ services; moreover, adolescents who have ever discussed
$\mathrm{RH}$ topics with their parents and well informed about $\mathrm{RH}$ issues were about $2(\mathrm{AOR}=2.4,95 \% \mathrm{CI}$ : 2.1-8.54) and 4 $(\mathrm{AOR}=4.33,95 \% \mathrm{CI}: 3.78-12.5)$ times more likely to use $\mathrm{RH}$ services respectively. The likelihood of $\mathrm{RH}$ services utilization was also significantly associated with RH knowledge $(\mathrm{AOR}=1.23,95 \% \mathrm{CI}: 1.23-4.21)$ (Table 6).

\section{Qualitative finding}

To complement the findings from quantitative data, six adolescents were interviewed by using IDI guide. Important findings were summarized, narrated and incorporated.

\section{Reproductive health knowledge and associated factors}

Misunderstanding of $\mathrm{RH}$ concepts was seen among the adolescents.

The IDI was started with general question that, 'what is $\mathrm{RH}$ ?', two of the six participants noted, as they did not know its meaning literally, while, gradually four of them indicated as it was a FP method.

Misconceptions regarding the ongoing physiological changes in reproductive health such as when to engage in sexual relation with opposite sex and what to do to avoid subsequent risks like unwanted pregnancy were not uncommon among rural adolescents.

\section{"I believe that a girl cannot become pregnant from a single act of sexual intercourse; therefore, to avoid pregnancy, some young men prefer to have sex in a causal relationship or have sex only once in a month with the same girl".}

Knowledge on SRH was found to be significant for adolescents even in their earlier age than expected in order to get ready to use the existing services.

"... for example, desire to have sexual relation with opposite sex starts approximately at

Table 5 Bivariate and multivariate analysis of socio-demographic and socio-economic characteristics and reproductive health services utilization among rural adolescents of Machakel district, northwest Ethiopia, February 2012

\begin{tabular}{|c|c|c|c|c|}
\hline \multirow[t]{2}{*}{ Factors } & \multicolumn{2}{|c|}{ RH services utilization } & \multirow[t]{2}{*}{ COR $[95 \% \mathrm{Cl}]$} & \multirow[t]{2}{*}{ AOR $[95 \% \mathrm{Cl}]$} \\
\hline & Yes & No & & \\
\hline \multicolumn{5}{|l|}{ Age (in years) } \\
\hline $15-19$ & $21(67.7)$ & $261(66.0)$ & $1.5(1.3-5.21)$ & $2.18(1.6-10.7)$ \\
\hline $10-14$ & $10(32.3)$ & $83(24.0)$ & 1.00 & 1.00 \\
\hline \multicolumn{5}{|c|}{ Level of school completed } \\
\hline Secondary & $20(64.5)$ & $139(61.0)$ & $0.57(0.48-0.93)$ & $2.41(1.42-4.1)$ \\
\hline Elementary & $11(35.5)$ & $134(39.0)$ & 1.00 & 1.00 \\
\hline \multicolumn{5}{|l|}{ Family size } \\
\hline$</=5$ & $18(58.0)$ & $125(36.0)$ & $1.81(0.13-1.46)$ & $2.23(1.09-6.87)$ \\
\hline$>5$ & $13(42.0)$ & $219(64.0)$ & 1.00 & 1.00 \\
\hline
\end{tabular}

Adjusted for sex, age, level of education and current schooling. 
Table 6 Bivariate and multivariate analysis of factors affecting reproductive health services utilization among rural adolescents of Machakel district, northwest Ethiopia, February 2012

\begin{tabular}{|c|c|c|c|c|}
\hline \multirow[t]{2}{*}{$\mathrm{RH}$-related factors } & \multicolumn{2}{|c|}{ RH services utilization } & \multirow[t]{2}{*}{ COR $(95 \% \mathrm{Cl})$} & \multirow[t]{2}{*}{ AOR $(95 \% \mathrm{Cl}$} \\
\hline & Yes & No & & \\
\hline \multicolumn{5}{|c|}{ Ever heard about RHS } \\
\hline Yes & $22(71.0)$ & $116(33.7)$ & $4.80(1.32-6.71)$ & $3.1(1.56-8.97)$ \\
\hline No & $9(29.0)$ & $228(66.3)$ & 1.00 & 1.00 \\
\hline \multicolumn{5}{|c|}{ Ever discussed RH topics } \\
\hline Yes & $19(61.3)$ & $103(30.0)$ & $3.70(1.89-5.68)$ & $2.4(2.1-8.54)$ \\
\hline No & $12(38.7)$ & $241(70.0)$ & 1.00 & 1.00 \\
\hline \multicolumn{5}{|c|}{ Well informed about RH issues } \\
\hline Yes & $24(77.4)$ & $106(30.8)$ & $7.69(3.2-10.21)$ & $4.33(3.78-12.5)$ \\
\hline No & 7 (22.6) & $238(69.2)$ & 1.00 & 1.00 \\
\hline \multicolumn{5}{|l|}{ RH knowledge } \\
\hline Yes & $23(74.2)$ & $228(66.3)$ & $1.46(1.35-4.23)$ & $1.23(1.1-4.21)$ \\
\hline No & $8(25.8)$ & $116(33.7)$ & 1.00 & 1.00 \\
\hline
\end{tabular}

about the age of five to ten; therefore, it is very important to introduce sexual education at this age to increase awareness about the ongoing conditions: when and how something happens and what to do if it comes to reality".

Most of the interviewees found it extremely difficult to discuss sexual matters with their parents. Some interviewees felt that if they talk about sex they made themselves more interested in exploring and practicing sex.

Moreover, adolescents feared that raising the topics of sexuality for discussion would interpret it as actual evidence of sexual involvement by their parents.

“...many cases I fear because my parents may think as I am becoming an unfaithful/bad girl”.

The IDI also revealed that the preferred sources of sex information were friends and peers.

"...I would prefer to get information from friends or relatives who are not harsh to me, those I do not fear and those I used to".

"...I prefer other young people with whom I can exchange ideas better than older people."

\section{Reproductive health services utilization and associated} factors

Using RH services such as condoms and pills was perceived as unsuitable for young people.
"We young people are not believed to use condoms, because our reproductive organs are still small; condoms are manufactured for adults only." "I do not think that these methods like pills are good for adolescents of our age group; when we use them they can harm our future fertility and if used for a long time there will be a lot of abortions".

The IDI also revealed that adolescents had little access to integrated RH services, where they could get appropriate $\mathrm{RH}$ services and information. Especially for the younger age groups, it was difficult to buy/collect condoms and pills due to non-friendly $\mathrm{RH}$ services providers and shame.

"...they think we are young and it is bad for us to use condoms". "...for collecting pills I would feel shy because everybody would know that I am going to play sex".

\section{Discussion}

To have access and use RH services, adolescents' level of knowledge is paramount. Advocating and increasing awareness about SRH is also crucial to the success of any adolescent reproductive health (ARH) effort. Hence, this study represented an initial effort to assess the SHR knowledge and services utilization status of adolescents in rural setting of Machakel district. It has tried to include adolescents aged between 10-19 years who were residing in the study area.

The relatively high non-response rate might be due to the sensitive nature of the topic incorporating sexuality issues which could not easily be revealed by most societies. 
Gonorrhea and HIV/AIDS were the major STI mentioned by the adolescents which is greater than EDHS (2011) report where only half of the rural Ethiopian adolescents have knowledge on HIV prevention methods [18]. Abstaining from sexual intercourse was the major means to prevent oneself from acquiring such infections. This finding is consistent with national ARH package where more than two-third of Ethiopian adolescents know a specific way to avoid the infection [10].

A person could not get HIV with the first sexual contact and through careful looking at a person HIV/AIDS status of an individual would be determined were reported by the adolescents. It is in accordance with results from Bangladesh where rural adolescents, particularly females, had a substantially lower level of knowledge about HIV/ AIDS compared to that of the urban counterparts (data not shown) $[19,20]$.

Health professionals were the main sources of information for RH. This finding is consistent with other studies in South Africa, Tanzania and Ghana [6,21,22].

Ever use of RH services is basically measured as the cumulative experience of adolescents with $\mathrm{RH}$ services. This study showed that there is a significantly lower $\mathrm{RH}$ services utilization rate among rural adolescents when it is compared with the study undertaken in Jimma where $41.1 \%$ ever experienced the services [15] even though the latter finding is not more comparable as it was undertaken in urban setting.

Seeking for FP showed significant increment (about 15 times) when it is compared with the situation before a decade in the same area which was only $2 \%$ [12]. The possible reason for this significant difference might be the effort of health extension program and health extension workers (HEW) in promoting and providing the services.

OCP was the commonest method used by the adolescents complementing the finding from Ghana where it is known by most adolescents (33.9\%) as the main FP methods [6]; moreover, consistent with the findings from Ghana and EDHS (2005), long-acting contraceptive methods were less likely used by the adolescents $[6,14]$. Knowledge of contraceptives and their utilization are important prerequisites to gaining access to and eventually adopting SRH services $[8,10]$.

Parent disapproval, lack of information and peer pressure hindered adolescents from accessing $\mathrm{RH}$ services. Consistent to this finding opposition from husband/relatives was reported as one of the reasons for not using FP methods among adolescents in Bangladesh [19].

Lack of awareness refrain adolescents from getting available RH services from health institutions. This points direction for risk assessment and designing health education and promotion programs pertinent to increasing awareness about these issues.
Three quarters of the adolescents had never discussed RH topics with their parents due to its worthlessness, fear, social and cultural. This complements the situation in Bangladesh where restrictive socio-cultural norms inhibit disclosure of information about sexual activities and other $\mathrm{RH}$-related issues to unmarried adolescents [20].

The odd of RH knowledge was higher among 15-19 years adolescents than 10-14 years. It reveals consistent finding of the study from India that shows significant association with RH knowledge of the rural adolescents [20]; the possible explanation would be as age increases exposure for $\mathrm{RH}$ related issues also increases. However, it contradicts with the finding from China [23].

Adolescents living with their grandparents and other relatives were more likely to know about RH issues. The possible explanation for this would be more freedom to communicate about SHR issues with relatives than biological families. Moreover, adolescents from rich families had more knowledge than poor families. The higher knowledge among the rich might be due to more exposure for such issues through mass media $[17,24]$ though this study did not show any significant association with the availability of means of communication and $\mathrm{RH}$ knowledge and services utilization. This finding is consistent with other studies from sub-Saharan African (SSA) countries $[17,24]$.

Education is significant social variable affecting $\mathrm{RH}$ service utilization. This finding is supported by studies in northwest Ethiopia and Kenya where higher educational status is positively associated with $\mathrm{RH}$ services utilization $[12,16,23]$. This is due to more disclosure for SRH information and secondary behavioral change.

However, being from rich family did not show any association with $\mathrm{RH}$ services utilization among the adolescents. It complements the findings of other studies in Ethiopia, Kenya and Bangladesh where income had no significant impact on RH services utilization [15] and contradicts the findings from SSA countries on the magnitude of socioeconomic inequalities in $\mathrm{RH}$ services utilization showing that contraceptive use was significantly less common among adolescents in the poorest quintile than in the richest [23]. One of the socio-demographic factors, sex, did not show association neither with RH knowledge nor services utilization as opposed to many studies showing male gender has more knowledge and the female counterpart having more tendencies to using $\mathrm{RH}$ services $[17,23]$.

\section{Conclusion}

In general, it was found that $\mathrm{RH}$ knowledge and services utilization amongst rural adolescents in the study area remained low as evidenced by only two-third of the adolescents had basic knowledge and one-fifth using available services for $\mathrm{RH}$. 
Socio-demographic and economic factors including age, level of education, living arrangement and being from well to do families were found to be predictors of RH knowledge and services utilization. Parent disapproval, lack of basic information for $\mathrm{RH}$ and parent pressure were found to deter adolescents from accessing $\mathrm{RH}$ services; moreover, low parent-adolescent communication on SRH issues continued to be socio-cultural taboos among the societies. According to this study, demographic, social and economic dynamics affecting adolescent reproductive health knowledge and services utilization should further be investigated.

\section{Abbreviations \\ AFRHS: Adolescent friendly reproductive health services; AIDS: Acquired immunodeficiency syndrome; $\mathrm{ARH}$ : Adolescent reproductive health; ASRH: Adolescent sexual and reproductive health; AOR: Adjusted odds ratio; COR: Crude odds ratio; EDHS: Ethiopian demographic and health survey; FP: Family planning; ICPD: International conference on population development; IDI: In-depth interview; IEC: Information, education and communication; HEW: Health extension workers; HIV: Human immunodeficiency virus; RH: Reproductive health; SRH: Sexual and reproductive health; SD: Standard deviation; SPSS: Statistical packages for social sciences; STI: Sexual transmitted infections; WHO: World Health Organization.}

\section{Competing interests}

The authors declared that there was no any conflict of interests.

\section{Authors' contributions}

The overall duty of this research has incorporated the multiple efforts of both authors from inception to accomplishment. AAA and AS carried out the conception and initiation, design, analysis and writing of this research article and involved in drafting of the manuscript. Both authors approved and agreed with its submission to BMC Health Services Research.

\section{Authors' information}

AAA is lecturer and public health researcher in Reproductive, Family Health and Nutrition Unit, Department of Public Health, Health Sciences College, Debremarkos University.

AS is assistant professor in Reproductive and Family Health, School of Public Health, Addis Ababa University.

\section{Acknowledgements}

We would like to thank Addis Ababa University School of Public Health for sponsoring this study.

We would like to thank Machakel district health department and its staffs, all data collectors, supervisors and participants who took part in the study.

\section{Author details}

'Public Health Department, Debremarkos University, P.O. Box: 269, Debremarkos, Ethiopia. ${ }^{2}$ Department of Reproductive and Family Health, School of Public Health, Addis Ababa University, Addis Ababa, Ethiopia.

Received: 17 March 2013 Accepted: 21 March 2014

Published: 29 March 2014

\section{References}

1. WHO: Programming for adolescent health and development report of WHO/ UNFPAVUNICEF study group on programming for adolescents health. Geneva: WHO; 1999.

2. World Health Organization and Deutsche Gesellschaft fuer Technische Zusammenarbeit (GTZ) GmbH: Sexually transmitted infections among adolescents: the need for adequate health services. Geneva: WHO Library Cataloguing-in-Publication Data; 2005

3. Shivaram K, Nandini C, Malleshappa1 K: Knowledge and attitude about reproductive health among rural adolescent girls in Kuppam mandal: an intervention study. Biomed Res 2011, 22(3):305-310.
4. Hughes J, McCauley AP: Improving the Fit: Adolescents' needs and future programs for sexual and reproductive health in developing countries studies in family planning. Studies in Family Planning 1998, 29(2):233-245.

5. UNFP: State of world population: making 1 billion count: investing in adolescent health and righrs. New York: UNFPA; 2003.

6. Health Unit, Association of Church-Based Development Program (ACDEP): A baseline survey on adolescent sexual and reproductive health in the operational areas of Ten ACDEP-member primary health care programmes in northern and upper east regions. Northern Region Ghana: project report; 2008.

7. Ayalew T, Meseret $Y$, Yeshigeta G: Reproductive health knowledge and attitude among adolescents: a community-based study in jimma town, southwest Ethiopia. Ethiop J Health Sci 2008, 22(3):143-151.

8. Butler PA: The reproductive health situation of adolescents. 64th edition. Progress in Reproductive Research; 2003:21-23.

9. FMoH: National reproductive health strategy, 2006-2015: national document. Addis Ababa, Ethiopia; 2006.

10. FMoH: Adolescent reproductive health extension package: national document Addis Ababa, Ethiopia; 2003.

11. Berhane F: Health problems and service preferences of school adolescents in Addis Ababa with emphasis on reproductive health (dissertation). Department of Community Health, Addis Ababa University; 2000 (unpublished masters thesis).

12. Alemayehu S, Fantahun M: Reproductive health needs of out-of-school adolescents: a cross-sectional comparative study of rural and urban areas in northwest Ethiopia. Ethiop.J.Health Dev 2006, 20(1):10-17.

13. Zhiyong L, Minmin Z, Hassen H, Zi L, Shuhua S, Zengzhen W: Reproductive health knowledge and services utilization among unmarried rural-tourban migrants in three major cities, China. BMC Public Health 2011 11(74). http://www.biomedcentral.com/1471-2458/11/74.

14. Central Statistical Agency (CSA): [Ethiopia] and ORC macro, Ethiopia demographic and health survey (2005). Addis Ababa, Ethiopia and Calverton, Maryland. USA: CSA and ORC Macro; 2006.

15. Ayalew T, Meseret $Y$, Yeshigeta G: Adolescent reproductive health services in jimma city: accessibility and utilization. Ethiop J Health Sci 2009, 19(2):91-102.

16. Fantahun M, Degu G: Health service utilization in Amhara region of Ethiopia. Ethiop J Health Dev 2003, 17(2):141-147.

17. Kotecha PV, Sangita V: Patel and Kalpita Shringarpure: reproductive health awareness among rural school going adolescents of vadodara district, Gujarat, Indian. J Psychatry 2012, 45(4):344-348.

18. Central Statistical Agency (CSA): [Ethiopia], MEASURE DHS, ICF macro Calverton, Maryland, and USA. Ethiopia Demographic and Health Survey (2011): Preliminary Report: Addis Ababa, Ethiopia; 2011.

19. Population Council, Associates for Community and Population Research (ACPR): Baseline survey of adolescent reproductive health interventions in Bangladesh; 2003.

20. Barkat A: Adolescent reproductive health in Bangladesh: status. Programs and Issues: Policies; 2003

21. Bana A, Bhat VG, Godlwana X, Libazi S, Maholwana Y, Maragungana N, Mona K, Mbonisweni AM, Mbulawa N, Mofuka J, Na M, Nondula NN, Qubekile Y, Ramnaran B: Knowledge, attitudes and behaviours of adolescents in relation to sexual transmitted infections, pregnancy, contraceptive utilization and substance abuse in the mhlakulo region, eastern cape. 2010, 52(2):154-158.

22. Van E: Use of antenatal services and delivery care among women in rural western Kenya: a community based survey. Reprod Health 2006, 3(2). http://www.reproductive-health-journal.com/content/3/1/2

23. Rani M, Lule E: Exploring the socioeconomic dimension of adolescent reproductive health: a multi-country analysis. Int Fam Plan Perspect 2004 30(3):110-117

24. Govindasamy P: Kidanu $A$ and Banteyerga $H$, youth reproductive health in Ethiopia. Calverton, Maryland: ORC Macro; 2002.

\section{doi:10.1186/1472-6963-14-138}

Cite this article as: Abajobir and Seme: Reproductive health knowledge and services utilization among rural adolescents in east Gojjam zone, Ethiopia: a community-based cross-sectional study. BMC Health Services Research 2014 14:138. 